\title{
Parenteral nutrition in the critically-ill patient: more harm than good?
}

\author{
D. K. Heyland \\ Department of Medicine and Department of Community Health and Epidemiology, Queen's University Faculty of \\ Health Sciences, Kingston, Ontario K7L 2V7, Canada
}

\begin{abstract}
While many studies have reported that providing parenteral nutrition (PN) can change nutritional outcomes, there are limited data that demonstrate that PN influences clinically-important end points in critically-ill patients. The purpose of the present paper is to systematically review and critically appraise the literature to examine the relationship between PN and morbidity and mortality in the critically-ill patient. Studies comparing enteral nutrition (EN) with PN and studies comparing PN with no PN were reviewed. The results suggest that EN is associated with reduced infectious complications in some critically-ill subgroups. PN, on the other hand, is associated with increased morbidity and mortality in critically-ill patients. When nutritional support is indicated, EN should be used preferentially over PN. Further studies are needed to define the optimal timing and composition of PN in patients not tolerating sufficient EN. Strategies to optimize EN delivery and minimize PN utilization in critically-ill patients are indicated.
\end{abstract}

\section{Parenteral nutrition: Enteral nutrition: Critically-ill}

\begin{abstract}
Amongst seriously-ill hospitalized patients malnutrition has been associated with increased infectious morbidity, prolonged hospital stay and increased mortality (Reinhardt et al. 1980; Chandra, 1983; Windsor \& Hill, 1988; Herrmann et al. 1992; Galanos et al. 1997). In critically-ill patients malnutrition results in impaired immunological function, impaired ventilatory drive and weakened respiratory muscles, leading to prolonged ventilatory dependence and increased infectious morbidity and mortality (Dark \& Pingleton, 1993). Furthermore, the metabolic response to critical illness (or hypercatabolism) can lead to severe wasting of the lean body mass, impairment of visceral organ function and a decrease in the body's reparative and immune function (Barton, 1994). Finally, beyond its digestive and absorptive capacities, the gastrointestinal tract is recognized for its immunological role and barrier function. Awareness of these associations and observations has led to the practice of providing nutritional support, either enterally (EN) or parenterally (PN), to critically-ill patients.

The administration of PN can clearly prevent the effects of starvation in patients with a non-functioning gastrointestinal tract (Dudrick et al. 1968). However, it is unclear whether PN can modulate the catabolic response to critical illness and reduce complications associated with hypercatabolism (Dempsey et al. 1988). In other terms, the administration of PN may result in significant improvement
\end{abstract}

in weight, $\mathrm{N}$ balance, pre-albumin levels and other nutritional end points, but the effect on clinically-important end points in critically-ill patients, such as mortality and complications, is less certain. However, some patients with an intact gastrointestinal tract do not tolerate enteral feeds or do not receive sufficient intake enterally or orally to meet their energy and protein requirements. PN is used as a supplement or as the only source of nutrition in these patients (American Society for Parenteral and Enteral Nutrition Board of Directors, 1993; Cerra et al. 1997). Evidence supporting this practice seems to be lacking (Deegan et al. 1999). The purpose of the present paper is to systematically review, critically appraise and statistically aggregate all studies evaluating the effect of $\mathrm{PN}$ on complication and mortality rates in critically-ill patients.

Critical appraisal of the evidence allows us to put forward clinical recommendations based on rules of evidence (Sackett, 1989). Strong clinical recommendations can be made (i.e. grade A recommendations) when supported by rigorous randomized trials in critically-ill patients with a low chance of error (level I evidence). Moderately-strong recommendations (grade B) can be made from randomized trials in critically-ill patients with a high risk of error (level II evidence). Weaker recommendations (grade C) are based on less-rigorous studies, or randomized trials in different patient populations, or randomized trials focusing on 
surrogate outcomes. Finally, no recommendations are made in the present paper from evidence that comes from non-randomized studies in non-critically-ill patients, animal studies or studies based on biological rationale. This relationship between levels of evidence and grades of recommendations is outlined in Table 1.

\section{Methods \\ Search strategy}

A computerized bibliographic search of Medline (including pre-Medline) from 1980 to 1999 to locate all relevant articles was conducted. The terms 'randomized controlled trial', 'double-blind method', 'clinical trial', 'placebo' and 'comparative study' were combined with 'exp parenteral nutrition, total', 'enteral nutrition', 'intensive care units' and 'critical care'. Citations were limited to English-language studies reporting on adult patients. Reference lists of relevant review articles and personal files were also searched.

\section{Study selection criteria}

Primary studies were selected for inclusion in the present review article if they met the following criteria:

(1) research design (randomized clinical trials);

(2) population (surgical or critically-ill adult human subjects);

(3) intervention (EN compared with PN, PN compared with no PN);

(4) outcome (infectious morbidity, length of stay and mortality).

As studies in which treatment is allocated by any other method than randomization tend to show larger (and frequently 'false-positive') treatment effects than do randomized trials (Sacks et al. 1983), only randomized trials were included in the present review. Patients undergoing

Table 1. Levels of evidence and grades of recommendations (modified, with permission, from Heyland et al. 1993)

\begin{tabular}{lc}
\hline Level of evidence & Grade of recommendation \\
\hline $\begin{array}{l}\text { Level 1: Randomized trial in seriously-ill } \\
\text { patients with low risk of error, i.e. } \\
\text { blinded, objective criteria, intention- }\end{array}$ & $\begin{array}{c}\text { Grade A: Supported by } \\
\text { level 1 evidence }\end{array}$ \\
$\begin{array}{cc}\text { to-treat analysis } \\
\text { Level II: Randomized trial in seriously-ill } \\
\text { patients with high risk of error, i.e. not }\end{array}$ & $\begin{array}{c}\text { Grade B: Supported by at } \\
\text { least one level II study }\end{array}$ \\
$\begin{array}{l}\text { blinded, objective criteria not used, } \\
\text { non-intention-to-treat analysis }\end{array}$ & \\
$\begin{array}{l}\text { Level III: Non-randomized trial of } \\
\text { seriously-ill patients or randomized }\end{array}$ & $\begin{array}{c}\text { Grade C: No support from } \\
\text { level I or II studies }\end{array}$ \\
trial of non-seriously-ill patients or & \\
randomized trial of seriously-ill & \\
patients measuring surrogate & \\
outcomes & \\
Level IV: Non-randomized trial in non- & No recommendation \\
seriously-ill patients or animal studies & \\
or biological rationale & \\
\hline
\end{tabular}

major surgery may not be cared for in a critical care environment in all cases, but share sufficient similarities in their response to illness that studies of surgical patients and critically-ill patients were combined. Studies of pediatric patients or neonates and studies of non-operative cancer patients were excluded. As the scope of the present review was defined by the research question, studies that only evaluated the impact of nutritional support on nutritional outcomes (i.e. $\mathrm{N}$ balance, amino acid profile etc.) were not included in the present paper. These end points were considered as surrogate end points (Fleming \& DeMets, 1996); only papers that reported on clinically-important outcomes (morbidity and mortality) were included in the present review.

Ineligible studies were included in the introduction of each section to provide supportive evidence, but were not used to derive treatment recommendations.

\section{Methodological quality of primary studies}

The methodological quality of all selected articles was assessed by considering the extent to which blinding was present, consecutive patients were enrolled in the trial, whether groups were equal at baseline, if co-intervention was adequately described, whether objective definitions of infectious outcomes were employed and whether all patients were properly accounted for in the analysis (intention-totreat analysis).

\section{Data extraction}

Data on methodological quality and outcomes were extracted from the primary papers. When data were missing or unclear, the primary investigators were contacted and requested to provide further information.

\section{Results}

What is the effect of enteral nutrition compared with parenteral nutrition with respect to clinically-important outcomes?

There have been a number of randomized trials in human populations comparing EN with PN. Studies in patients undergoing head and neck surgery (Sako et al. 1981), liver transplantation (Wicks et al. 1994), major upper gastrointestinal surgery (Lim et al. 1981; Bower et al. 1986; Hamaoui et al. 1990; Baigrie et al. 1996) and patients with multiple organ dysfunction (Cerra et al. 1988) have demonstrated that enteral feeding is feasible, safe, cheaper and results in similar nutritional outcomes compared with PN. Compared with PN, critically-ill patients receiving EN have demonstrated better wound healing (Schroeder et al. 1991) and a decrease in gastrointestinal tract mucosal permeability (Hadfield et al. 1995).

There are only a few studies that evaluate the relative merits of EN and PN in critically-ill patients and report on clinically-important outcomes. In trauma patients there were two small studies that found no difference between EN and PN (Adams et al. 1986; Dunham et al. 1994). Moore et al. (1989) found that enteral feeding resulted in similar $\mathrm{N}$ 
balance and energy intake compared with PN. However, they also found a lower incidence of major septic morbidity in the enterally-fed group. Seventy-five patients undergoing emergent laparotomy for blunt trauma were randomized to PN or EN. Objective criteria were used to define infectious outcomes, although investigators and clinicians were not blinded to treatment group allocation. Sixteen patients were excluded after randomization, leaving fifty-nine evaluable subjects. Five of twenty-nine $(17 \%)$ from the PN group compared with eleven of thirty (37\%) from the PN group $(P>0.05)$ developed septic complications. However, only one patient $(3 \%)$ in the EN group developed an intraabdominal abscess compared with six patients $(20 \%)$ in the PN group who developed major septic complications (two had abdominal abscess, six had pneumonia, in the six patients; $P=0.03$ ).

Kudsk et al. (1992) repeated the latter study in trauma patients with a broader range of severity of illness. In this randomized unblinded study using objective criteria to define outcomes, ninety-eight patients with abdominal trauma were allocated to enteral or parenteral feeding within $24 \mathrm{~h}$ of injury. Nine of fifty-one $(15.7 \%)$ of those patients who received EN developed septic complications compared with eighteen of forty-five $(40 \%)$ of the patients receiving $\mathrm{PN}(P<0 \cdot 02)$.

Moore et al. (1992) aggregated the results of eight studies, including six unpublished trials to evaluate EN compared with PN in surgical and trauma patients. The unpublished trials were not blinded, and septic complications were determined by a retrospective chart review without explicit criteria. Studies also varied in the nutritional formula used and the time of initiating nutritional support. When analysed according to the intention-to-treat method, the overall results showed that nineteen of 118 (16\%) patients receiving EN developed infectious complications compared with thirty-nine of $112(35 \%)$ receiving $\mathrm{PN}(P=0 \cdot 03)$.

In head-injured patients, the benefits of EN over PN are not as apparent. Two small studies of patients with head trauma did not detect a difference in nutritional and clinical outcomes between PN and EN (Hadley et al. 1986; Borzotta et al. 1994). Rapp et al. (1983) conducted a trial of thirtyeight head-injured patients who were randomly allocated to receive PN within $48 \mathrm{~h}$ or EN when bowel sounds were present. There was a significant difference in the $\mathrm{N}$ intake between the two groups, resulting in an improved $\mathrm{N}$ balance in those patients who received PN. Infectious outcomes were not reported. Nine of eighteen $(50 \%)$ patients fed enterally died, primarily of infectious causes, compared with three of thirty $(15 \%)$ patients who received PN. Later, this same research group repeated this study in fifty-one head-injured patients (Young et al. 1987). In this study, they again demonstrated a difference in nutritional outcomes, but there was no difference in overall infections and mortality between the two groups. However, patients fed enterally had a much higher incidence of aspiration pneumonia (nine of twenty-eight patients, $32 \%$ ) compared with patients receiving $\mathrm{PN}$ (three of twenty-three, $13 \% ; P=0 \cdot 11$ ). It is hypothesized that head-injured patients have impaired gastric emptying (Ott et al. 1991) and lower oesophageal sphincter dysfunction (Saxe et al. 1994), placing them at high risk for aspiration pneumonia. In both studies patients with better nutritional variables had a better neurological recovery. Thus, the differences in clinical outcome could be ascribed to differences in energy and protein intake rather than differences in route of administration of nutrients. However, in another study of forty-five patients with head trauma, despite better energy intake and a more positive $\mathrm{N}$ balance associated with $\mathrm{PN}$, there was no difference in clinical outcomes.

There are three small randomized controlled trials that compare the safety and efficacy of EN and PN in patients with acute pancreatitis. McClave et al. (1997) found nasojejunal feedings to be equally as safe and significantly less costly than PN, but were unable to demonstrate differences in complication rates or length of stay. Windsor et al. (1998) demonstrated that EN favourably modifies the inflammatory response associated with pancreatitis and results in a reduction in the requirement for intensive care and incidence in organ failure. Finally, Kalfarentzos et al. (1997) demonstrated that patients with acute severe pancreatitis fed enterally experienced fewer total complications (44\% $v$. $75 \% ; P<0.05)$ and fewer septic complications $(25 \% v$. $50 \% ; P<0 \cdot 01)$.

Summary. Randomized trials demonstrate that EN is associated with lower costs, improved nutritional outcomes, less mucosal permeability and greater wound healing than patients fed with PN (level III evidence). Small unblinded studies show a decrease in septic morbidity in enterally-fed patients with abdominal trauma and patients with pancreatitis (level II evidence).

In patients with pancreatitis or abdominal trauma, where possible, EN should be used preferentially over PN to meet the nutritional requirements of critically-ill patients (grade B recommendation). In head-injured patients either EN or PN would be an acceptable method of providing nutritional support (grade B recommendation). In all other critically-ill patients EN is the preferred method of providing nutritional support (grade $\mathrm{C}$ recommendation).

\section{Impact of parenteral nutrition compared with no parenteral nutrition on mortality and complications rates}

There are twenty-six randomized trials involving 2211 patients that compare the use of $\mathrm{PN}$ with standard care (usual oral diet plus intravenous fluids) in patients undergoing surgery (Abel et al. 1976; Holter \& Fischer, 1977; Freund et al. 1979; Lim et al. 1981; Thompson et al. 1981; Yamada et al. 1983; Askanzi et al. 1986; Bower et al. 1986; Bellatone et al. 1988; Cerra et al. 1988; Meguid et al. 1988; Smith \& Hartemink, 1988; Woolfson \& Smith, 1989; Gys et al. 1990; Hamaoui et al. 1990; Schroeder et al. 1991; Von Meyenfeldt et al. 1992; Brennan et al. 1994; Fan et al. 1994; Hadfield et al. 1995; Jimenez et al. 1995; Baigrie et al. 1996), patients with pancreatitis (Sax et al. 1987), patients in an intensive care unit (Chiarelli et al. 1996) and patients with severe burns (Herndon et al. 1989). The details of individual studies, including the methodological quality score of each study, are described in Table 2. When the results of these trials were aggregated (Heyland et al. 1998), PN had no effect on mortality (risk ratio (RR) $1.03,95 \%$ CI $0 \cdot 81,1 \cdot 31$; see Fig. 1). The test for heterogeneity was not 


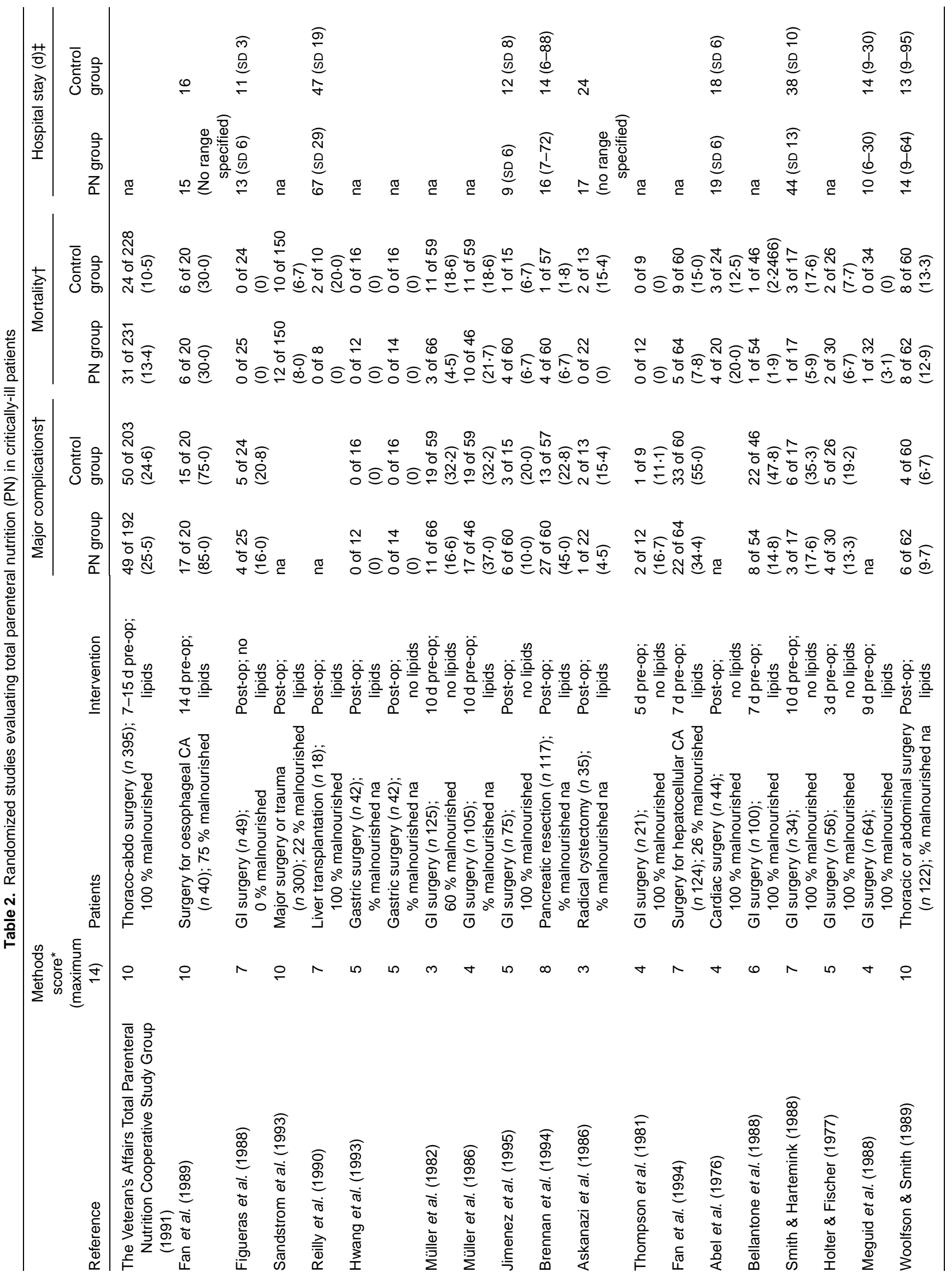




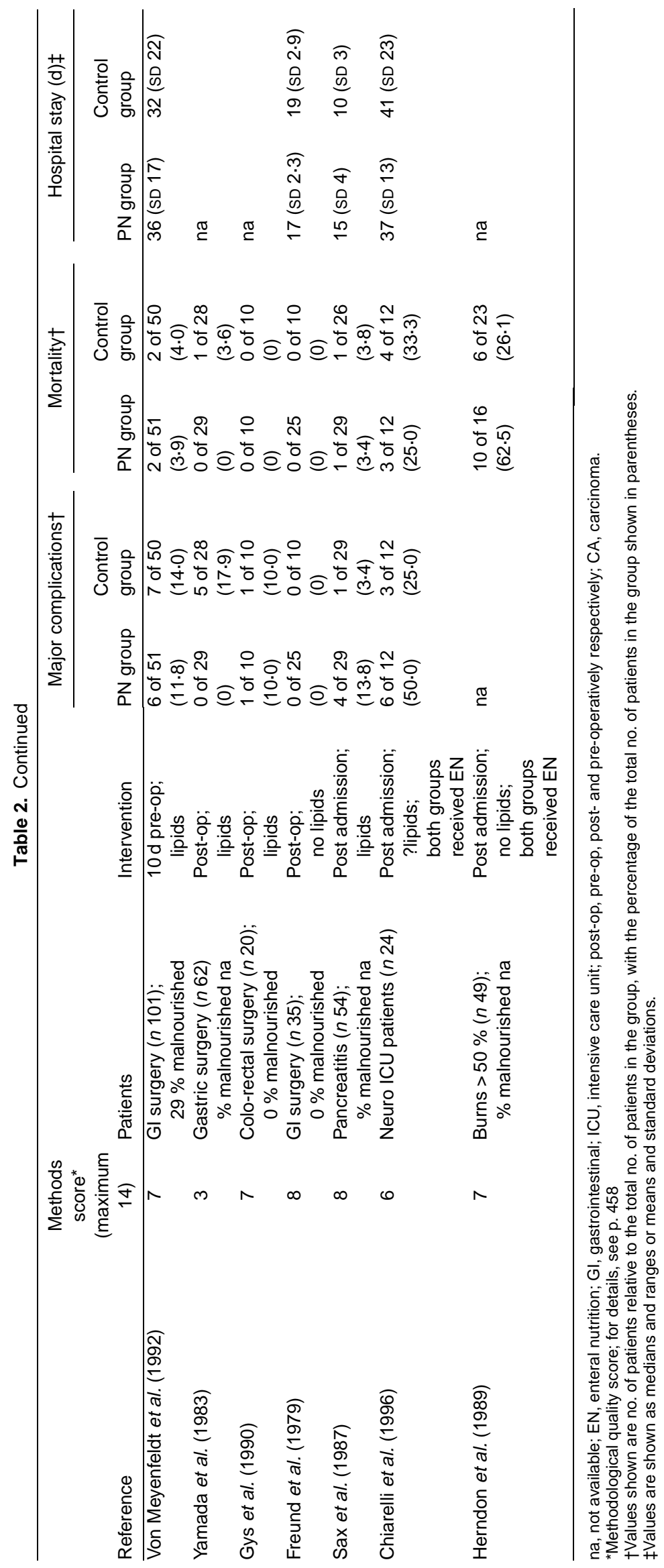


significant $(P=0.59)$, although a visual inspection of Fig. 1 suggests that the treatment effects are variable.

Twenty-two studies reported major complications in study patients. When these results were aggregated there was a trend towards a reduction in complication rates in patients receiving PN (RR 0.84, $95 \%$ CI 0.64, 1.09; Fig. 2). The test for heterogeneity was significant $(P=0.003)$.

To better understand these findings, several a priori hypotheses were explored. First, those trials that included only malnourished patients were compared with other trials. There was no difference in mortality (see Fig. 3) between studies of malnourished patients (RR 1.13, $95 \%$ CI 0.75 , 1.71) and studies that included adequately-nourished patients (RR 1.00, $95 \%$ CI 0.71, 1.39; for differences between subgroups $P=0 \cdot 64$ ). The rate of major complications was significantly lower among malnourished patients receiving $\mathrm{PN}(\mathrm{RR} 0 \cdot 52,95 \% \mathrm{CI} 0 \cdot 30,0 \cdot 91)$. There was no difference in complication rates among studies of adequately-nourished patients (RR 1.02, $95 \%$ CI 0.75 , 1.40). The difference in complication rates between these subgroups was significant $(P=0 \cdot 05)$.

Next, trials with a methodological quality score of $<7$ were compared with trials with a score of $\geq 7$ (see Fig. 3). Trials with the higher score demonstrated no effect of PN on mortality (RR $1 \cdot 17,95 \%$ CI $0 \cdot 88,1 \cdot 56)$. There was a trend towards a lower mortality rate in studies with a lower methodological quality score (RR 0.76, $95 \%$ CI $0 \cdot 49,1 \cdot 19)$. The difference between these two subgroups was not within conventional levels of significance $(P=0 \cdot 12)$. With respect to complication rates, studies with a higher score demonstrated no treatment effect (RR 1.13, $95 \%$ CI $0 \cdot 86$, 1.50). Studies with a lower score showed a significant reduction in complication rates associated with PN (RR $0.54,95 \%$ CI $0.33,0.87)$. The difference in complication rates between these subgroups was significant $(P=0 \cdot 02)$.

Trials published before 1989 were then compared with trials published in 1989 or later (see Fig. 3). Trials published in 1988 or earlier demonstrated a trend towards a lower mortality associated with PN (RR $0 \cdot 70,95 \%$ CI $0 \cdot 44,1 \cdot 13)$. Trials published since 1989 demonstrated no treatment effect (RR 1.18, $95 \%$ CI 0.89, 1.57). Differences between these two subgroups were not within conventional levels of statistical significance $(P=0 \cdot 07)$. With respect to complication rates, in studies published in 1988 or earlier there were significantly fewer major complications associated with PN (RR 0.49, $95 \%$ CI 0.29, 0.81), while the studies published since 1989 showed no effect of PN on complication rates (RR 1.19, $95 \%$ CI $0.93,1.53$ ). The difference between these subgroups was significant $(P=0.005)$.

Studies that provided intravenous lipids as a component of PN administration were also compared with those studies

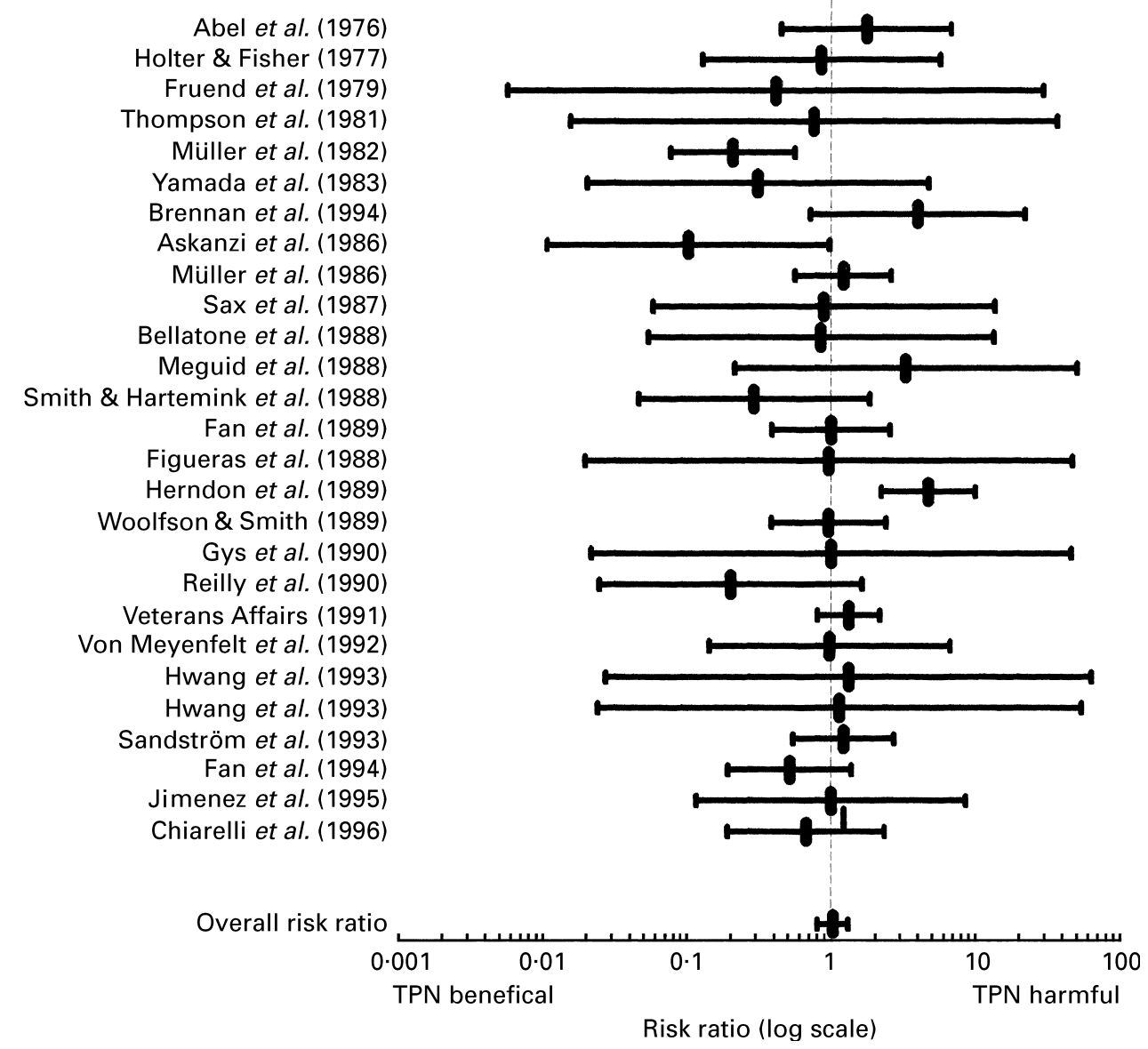

Fig. 1. Risk ratios and associated $95 \% \mathrm{Cl}$, represented by horizontal bars, for the effect of total parenteral nutrition (TPN) on mortality in critically-ill patients.Veterans Affairs (1991), The Veterans Affairs Total Parenteral Nutrition Cooperative Study Group (1991). (From Heyland et al. 1998.) 
Holter et al. (1977)

Fruend et al. (1979)

Thompson et al. (1981)

Müller et al. (1982)

Yamada et al. (1983)

Brennan et al. (1994)

Askanzi et al. (1986)

Muiller et al. (1986)

Sax et al. (1987)

Bellatone et al. (1988)

Smith \& Hartemink (1988)

Fan et al. (1989)

Figueras et al. (1988)

Woolfson \& Smith (1989)

Gys et al. (1990)

Veterans Affairs (1991)

Von Meyenfelt et al. (1992)

Hwang et al. (1993)

Hwang et al. (1993)

Fan et al. (1994)

Jimenez et al. (1995)

Chiarelli et al. (1996)

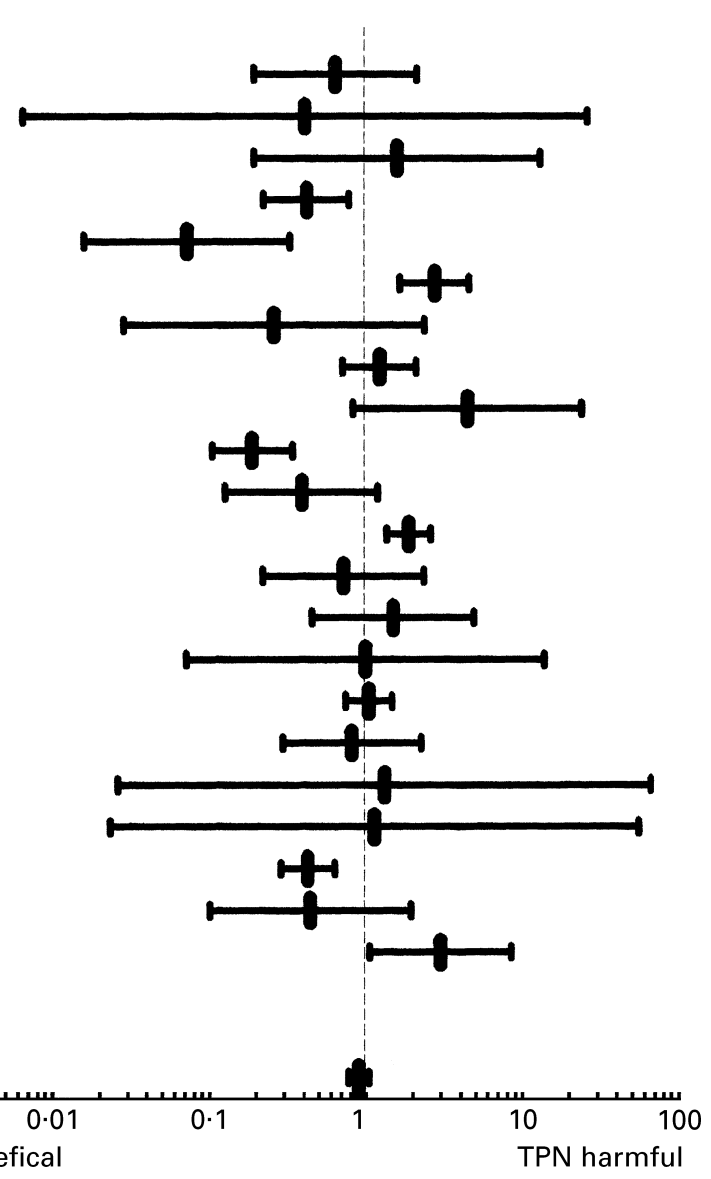

Risk ratio (log scale)

Fig. 2. Risk ratios and associated $95 \% \mathrm{Cl}$, represented by horizontal bars, for the effect of total parenteral nutrition (TPN) on rate of major complications in critically-ill patients, Veterans Affairs (1991), The Veterans Affairs Total Parenteral Nutrition Cooperative Study Group (1991). (From Heyland et al. 1998.)

that did not include lipids. In studies that used lipids (RR $1.03,95 \%$ CI $0.78,1.36$ ) compared with those studies that did not (RR $0.98,95 \%$ CI $0.49,1.95)$ there was no difference in mortality (for the difference between subgroups $P=0 \cdot 89$ ). With respect to complication rates, studies that used lipids compared with standard care demonstrated no effect (RR 0.96, $95 \%$ CI 0.69, 1.34). In studies of PN that did not contain lipids, the complication rate was significantly lower (RR $0 \cdot 59,95 \%$ CI $0 \cdot 38,0 \cdot 90$ ). The difference between these subgroups was just outside conventional levels of significance $(P=0 \cdot 09)$.

Finally, studies of critically-ill patients (patients cared for in a critical care environment) were compared with studies of primarily surgical patients. With respect to mortality, there was a higher mortality in critically-ill patients receiving PN (RR 1.78, $95 \%$ CI 1.11, 2.85), while studies of surgical patients showed no treatment effect (RR 0.91, $95 \%$ CI $0.68,1.21)$. The differences between these groups was statistically significant $(P=0 \cdot 03)$. With respect to complication rates, there was a trend towards an increase in complication rate in the studies of critically-ill patients (only two studies reported complication rates; RR 2.40, $95 \%$ CI $0.88,6.58)$, while studies of surgical patients were associated with lower complication rates (RR 0.76, $95 \%$ CI $0.48,1.0)$. The difference between these subgroups was significant $(P=0 \cdot 05)$.

Only fourteen studies reported the impact of $\mathrm{PN}$ on duration of stay in hospital; five reporting median stay, nine reporting mean stay. In eight studies the duration of stay in hospital was shorter in the control group. Due to the variability in duration of stay and variability of reporting methods, we did not statistically aggregate these results but they are displayed in Table 2.

Summary. A meta-analysis of several level I and level II randomized trials fails to demonstrate any significant difference in morbidity and mortality associated with the supplemental use of PN. There may be a reduction in complication rates in malnourished patients, but this reduction is not supported by recent trials nor trials with higher methodological quality scores. The results of the subgroup analysis suggest that both mortality and complication rates may be increased in critically-ill patients receiving $\mathrm{PN}$, and these treatment effects may differ from the results in surgical patients. Thus, there are no data from randomized trials to support the use of $\mathrm{PN}$ in patients with an intact gastrointestinal tract (grade A recommendation). 


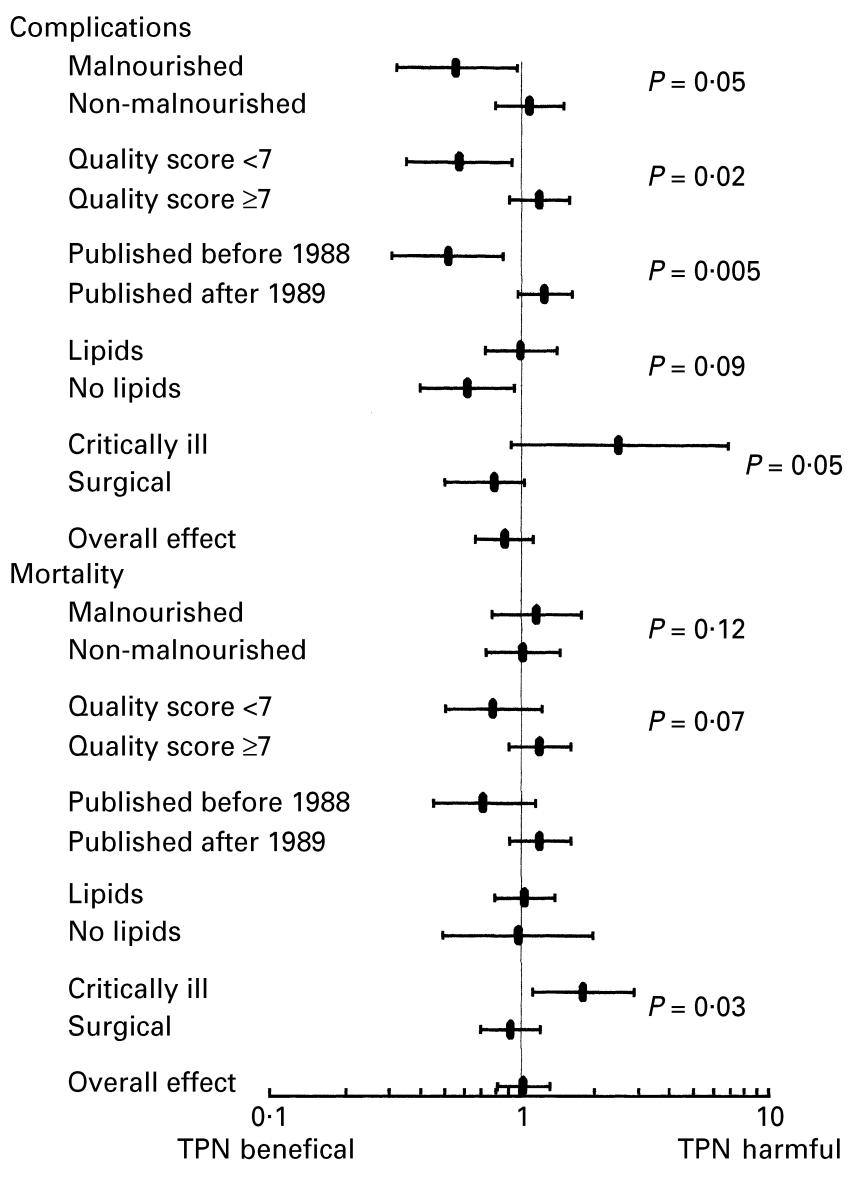

Risk ratio (log scale)

Fig. 3. Results of subgroup analysis examining the effect of total parenteral nutrition (TPN) on mortality and complication rates in critically-ill patients. Values are risk ratios and $95 \% \mathrm{Cl}$, represented by vertical bars. $P$ values represent a test of heterogeneity across subgroups. (From Heyland et al. 1998.)

\section{Conclusion}

The pioneering work of many investigators has led us to understand the important role that malnutrition and nutrition plays in critical illness. While providing nutritional support to seriously-ill patients can alter nutritional outcomes, there are few randomized controlled trials demonstrating that any form of nutritional support improves the morbidity and mortality of such patients. Moreover, the majority of studies demonstrating any benefit to nutritional support are in surgical or severely-traumatized patients. Yet, in practice, we generalize this data to all types of critically-ill patients.

It would appear that EN is associated with a reduction in infectious complications, especially in patients with trauma and pancreatitis. In other patient populations data are insufficient to make strong conclusions about the benefits of EN over PN. However, the studies that compare the use of PN with no PN (standard care plus intravenous fluids) suggest that PN may be associated with increased morbidity and mortality in critically-ill patients. For the patient with an intact gastrointestinal tract $\mathrm{PN}$ is not recommended for routine use. Further studies are needed to clarify the optimal timing and composition of $\mathrm{PN}$ in patients who do not tolerate sufficient energy enterally. Consistent with findings of the present review, there are some experimental and clinical data that suggest that intravenously-administered lipid emulsions may have an adverse effect on immune function and clinical outcomes (Seidner et al. 1989; Basttistella et al. 1997).

In the absence of further data clarifying the role of $\mathrm{PN}$ in critically-ill patients, strategies to optimize the use of EN and minimize the use of PN need to be further evaluated. Up to $60 \%$ of patients receiving nutrition support in intensive care units across Europe are receiving PN (Preiser et al. 1999). There is tremendous cross country (and probably cross hospital) variation in utilization of PN. In one hospital, using a multi-disciplinary multifaceted approach to providing nutrition support, clinicians were able to reduce the use of PN from $61 \%$ of critically-ill patients receiving nutrition support in 1992 to $11 \%$ in 1998 (Keefe et al. 2000). Aligning the provision of nutrition support to critically-ill patients with the 'best evidence' available currently will probably result in improved clinical outcomes and significant cost savings.

\section{References}

Abel RM, Fischer JE, Buckley MJ, Barnett GO \& Austen WG (1976) Malnutrition in cardiac surgical patients. Archives of Surgery 111, 45-50.

Adams S, Dellinger EP, Wertz MJ, Orekovich MR, Simonowitz D \& Johansen K (1986) Enteral versus parenteral nutritional support following laparotomy for trauma: A randomized prospective trial. Journal of Trauma 26, 882-890.

Askanzi J, Starker PM, Olsson C, Hensels TW, Lockart SH, Kinney JM \& Lasala PA (1986) Effect of immediate postoperative nutritional support on length of hospitalization. Annals of Surgery 203, 236-239.

American Society for Parenteral and Enteral Nutrition Board of Directors (1993) Guidelines for the use of parenteral and enteral nutrition in adult and pediatric patients. Journal of Parental and Enteral Nutrition 17, 1SA-52SA.

Baigrie RJ, Devitt PG \& Watkin DS (1996) Enteral versus parenteral nutrition after oesophagogastric surgery: A prospective randomized comparison. Australian and New Zealand Journal of Surgery 66, 668-670.

Barton RG (1994) Nutrition support in critical illness. Nutrition in Clinical Practice 9, 127-139.

Basttistella FD, Widergren JT, Anderson JT, Siepler JK, Weber JC \& MacColl K (1997) A prospective, randomized trial of intravenous fat emulsion administration in trauma victims requiring total parenteral nutrition. Journal of Trauma 43, 52-58.

Bellatone R, Doglietto GB, Bossola M, Pacelli F, Negro F, Sofo L \& Crucitti F (1988) Preoperative parenteral nutrition in the high risk surgical patient. Journal of Parenteral and Enteral Nutrition 12, 195-197.

Borzotta AP, Pennings J, Papasadero B, Paxton J, Mardesic S, Barzotta R, Parrott A \& Bledsoe F (1994) Enteral versus parenteral nutrition after severe closed head injury. Journal of Trauma 37, 459-468.

Bower RH, Talamini MA, Sax HC (1986) Postoperative enteral nutrition vs parenteral nutrition. A randomized controlled trial. Archives of Surgery 121, 1040-1045.

Brennan MF, Pesters PWT, Posner M, Quesada O \& Shike M (1994) A prospective randomized trial of total parenteral nutrition after major pancreatic resection for malignancy. Annals of Surgery 220, 436-444. 
Cerra FB, Benitez RB, Blackburn GL, Irwin RS, Jeejeebhoy K, Katz DP, Pingleton SK, Pomposelli J, Roinbeau JL, Shronts E, Wolfe RR \& Zaloga GP (1997) Applied nutrition in ICU patients: A consensus statement of the American College of Chest Physicians. Chest 111, 769-778.

Cerra FB, McPherson JP, Konstantinides FN, Konstantinides NN \& Teasley KM (1988) Enteral nutrition does not prevent multiple organ failure syndrome (MOFS) after sepsis. Surgery 104, 727-733.

Chandra RK (1983) Nutrition, immunity and infection: present knowledge and future direction. Lancet i, 688-691.

Chiarelli AG, Ferrarello S, Piccioli A, Abate A, Chini G, Berioli MB, Peris A \& Lippi R (1996) Total enteral nutrition versus mixed enteral and parenteral nutrition in patients in an intensive care unit. Minerva Anesthesiology 62, 1-7.

Dark DS \& Pingleton SK (1993) Nutrition and nutritional support in critically ill patients. Journal of Intensive Care Medicine $\mathbf{8}$, 16-33.

Deegan H, Dent S, Heyland DK, Keefe L \& Drover JW (1999) Supplemental parenteral nutrition in the critically ill patient: A retrospective study. Clinical Intensive Care 10, 131-136.

Dempsey DT, Mullen JL \& Buzby GP (1988) The link between nutritional status and clinical outcome: can nutritional intervention modify it? American Journal of Clinical Nutrition 47, 352-356.

Dudrick SJ, Wilmore DW, Vars HM \& Rhoads J (1968) Long-term total parenteral nutrition with growth, development and a positive nitrogen balance. Surgery 64, 134-142.

Dunham CM, Frankenfield D, Belzberg H (1994) Gut failure predictor of or contributor to mortality in mechanically ventilated blunt trauma patients? Journal of Trauma 37, 30-34.

Fan S, Lo C \& Lai ECS (1994) Perioperative nutritional support in patients undergoing hepatectomy for hepatocellular carcinoma. New England Journal of Medicine 331, 1547-1552.

Fan ST, Lau WY, Wong KK \& Chan YPM (1989) Preoperative parenteral nutrition in patients with oesophageal cancer: a prospective randomized clinical trial. Clinical Nutrition 8 , 23-27.

Figueras J, Rafecao A, Bianchi A, Hernandez F, Pi F \& Colomer J (1988) Postoperative hypocaloric parenteral nutrition. Acta Chirurgica Scandinavica 154, 435-438.

Fleming TR \& DeMets DL (1996) Surrogate end points in clinical trials: Are we being misled? Annals of Internal Medicine 125, 605-613.

Freund H, Hoover HC, Atamian S \& Fischer JE (1979) Infusion of the branched chain amino acids in postoperative patients. Annals of Surgery 190, 18-23.

Galanos AN, Pieper CF, Kussin PS, Winchell MT, Fulkerson WJ, Harrell FE Jr, Teno JM, Layde P, Connors AF Jr, Phillips RS \& Wenger NS (1997) Relationship of body mass index to subsequent mortality among seriously ill hospitalized patients. Critical Care Medicine 25, 1962-1968.

Gys T, Peeters R \& Hubens A (1990) The value of short-term peripheral parenteral nutrition after colorectal surgery: a comparative study with conventional postoperative intravenous fluid. Acta Chirurgica Belgica 90, 234-239.

Hadfield RJ, Sinclair DG, Houldsworth PE \& Evans TW (1995) Effects of enteral and parenteral nutrition on gut mucosal permeability in the critically ill. American Journal of Respiratory Critical Care Medicine 152, 1545-1548.

Hadley MN, Grahm TW, Harrington T, Schiller WR, McDermott MK \& Posillico DB (1986) Nutritional support and neurotrauma: A critical review of early nutrition in forty-five acute head injury patients. Neurosurgery 19, 367-373.

Hamaoui E, Lefkowitz R, Olender L, Krasnopolsky-Levine E, Favale M, Webb H \& Hoover EL (1990) Enteral nutrition in the early postoperative period: A new semi-elemental formula versus total parenteral nutrition. Journal of Parental and Enteral Nutrition 14, 501-507.

Herndon DN, Barrow RE, Stein M, Linares H, Rutan TC, Rutan R $\&$ Abston S (1989) Increased mortality with intravenous supplemental feeding in severely burned patients. Journal of Burn Care and Rehabilitation 10, 309-313.

Herrmann FR, Safran C, Levkoff SE \& Minaker KL (1992) Serum albumin level on admission as a predictor of death, length of stay, and readmission. Archives of Internal Medicine 152, 125-130.

Heyland DK, Cook DJ \& Guyatt G (1993) Enteral nutrition in the critically-ill patient: a review. Intensive Care Medicine 19, 435-442.

Heyland DK, MacDonald S, Keefe L \& Drover JW (1998) Total parenteral nutrition in the critically ill patient: A meta-analysis. Journal of the American Medical Association 280, 2013-2019.

Holter AR \& Fischer JE (1977) The effects of perioperative hyperalimentation on complications in patients with carcinoma and weight loss. Journal of Surgical Research 23, 31-34.

Hwang TL, Mou SC \& Chen MF (1993) The importance of a source of sufficient protein in postoperative hypocaloric partial parenteral nutritional support. Journal of Parenteral and Enteral Nutrition 17, 254-256.

Jimenez FJ, Leyba CO, Jimenez LMJ, Valdecasas MSG \& Montro JG (1995) Study of hypocaloric peripheral parenteral nutrition in postoperative patients. Clinical Nutrition 14, 88-96.

Kalfarentzos F, Kehagias J, Mead N, Kokkinis K \& Gogos CA (1997) Enteral nutrition is superior to parenteral nutrition in severe acute pancreatitis: Results of a randomized prospective trial. British Journal of Surgery 84, 1665-1669.

Keefe L, Drover JW \& Heyland DK (2000) Use of a multidisciplinary, multifaceted approach to aligning nutrition practice with a 'best practice in a critical care' setting: Results of a seven year study. Journal of Parental and Enteral Nutrition (In the Press).

Kudsk KA, Croce MA, Fabian TC, Minard G, Tolley EA, Poret A, Kuhl MR \& Brown RO (1992) Enteral versus parenteral feeding. Annals of Surgery 215, 503-513.

Lim STK, Choa RG, Lam KH, Wong J \& Ong GB (1981) Total parenteral nutrition versus gastrostomy in the preoperative preparation of patients with carcinoma of the oesophagus. British Journal of Surgery 68, 69-72.

McClave SA, Greene L, Snider H, Makk LJK, Cheadle WG, Owens NA, Dukes LG \& Goldsmith LJ (1997) Comparison of the safety of early enteral vs parenteral nutrition in mild acute pancreatitis. Journal of Parenteral and Enteral Nutrition 21, 14-20.

Meguid MM, Curtas MS \& Meguid V (1988) Effects of preoperative TPN on surgical risk preliminary status report. British Journal of Clinical Practice 42, Suppl., 53-58.

Moore FA, Feliciano DV, Andrassy RJ, McArdle AH, McL Booth F, Morgenstein-Wagner TB, Kellum JM Jr, Welling RE \& Moore EE (1992) Early enteral feeding, compared with parenteral, reduces postoperative septic complications. The results of a meta-analysis. Annals of Surgery 216, 172-183.

Moore FA, Moore EE, Jones TN, McCroskey BL \& Petersen VM (1989) TEN versus TPN following major abdominal trauma reduced septic morbidity. Journal of Trauma 29, 916-923.

Müller JM, Brenner U, Dienst C \& Pichlmaier (1982) Preoperative parenteral feeding in patients with gastrointestinal carcinoma. Lancet i, 68-71.

Müller JM, Keiler HW, Brenner U, Walter M \& Holzmüller W (1986) Indications and effects of preoperative parenteral nutrition. World Journal of Surgery 10, 53-63.

Ott L, Young B, Phillips R, McClain C, Adams L, Dempsey R, Tibbs P \& Ryo UY (1991) Altered gastric emptying in the headinjured patient: relationship to feeding intolerance. Journal of Neurosurgery 74, 738-742. 
Preiser JC, Berre J, Carpentier Y, Jolliet P, Pichard C, Van Gossum A \& Vincent JL (1999) Management of nutrition in European intensive care units: results of a questionnaire. Intensive Care Medicine 25, 95-101.

Rapp RP, Young B, Twyman D, Bivins BA, Haack D, Tibbs PA \& Bean JR (1983) The favorable effect of early parenteral feeding on survival in head-injured patients. Journal of Neurosurgery 58, 906-912.

Reilly J, Mehta R, Teperman L, Cemaj S, Tzakis A, Yanaga K, Ritter P, Rezak A \& Makowka L (1990) Nutritional support after liver transplantation: A randomized prospective study. Journal of Parenteral and Enteral Nutrition 14, 386-391.

Reinhardt GF, Myscofski JW, Wilkens DB, Dobrin PB, Mangan JE Jr \& Stannard RT (1980) Incidence and mortality of hypoalbumenic patients in hospitalized veterans. Journal of Parental and Enteral Nutrition 4, 357-359.

Sackett DL (1989) Rules of evidence and clinical recommendations on the use of antithrombotic agents. Chest $95,2 \mathrm{~S}-4 \mathrm{~S}$.

Sacks HS, Chalmers TC \& Smith H Jr (1983) Randomized versus historical assignment in controlled trials. New England Journal of Medicine 309, 1353-1361.

Sako K, Lore JM, Kaufman S, Razack MS, Bakamijan V \& Reese P (1981) Parenteral hyperalimentation in surgical patients with head and neck cancer: A randomized study. Journal of Surgical Oncology 16, 391-402.

Sandström R, Drott, Hyttander A, Arfuidsson B, Scherstén T, Wickström I \& Lundholm K (1993) The effect of postoperative intravenous feeding (TPN) on the outcome following major surgery evaluated in a randomized study. Annals of Surgery 217, $185-195$.

Sax HC, Warner BW, Talamini MA, Hamilton FN, Bell RH Jr, Fischer JE \& Bower RH (1987) Early total parenteral nutrition in acute pancreatitis: Lack of beneficial effects. American Journal of Surgery 153, 117-123.

Saxe JM, Ledgerwood AM, Lucas CE \& Lucas WF (1994) Lower esophageal sphincter dysfunction precludes safe gastric feeding after head injury. Journal of Trauma 37, 581-584.

Schroeder D, Gillanders L, Mahr K \& Hill GL (1991) Effects of immediate postoperative enteral nutrition on body composition, muscle function, and wound healing. Journal of Parental and Enteral Nutrition 15, 376-383.
Seidner DL, Mascoli EA, Istfan NW, Porter KA, Selleck K, Blackburn GL \& Bistrian BR (1989) Effects of long-chain triglyceride emulsions on reticuloendothelial system function in humans. Journal of Parental and Enteral Nutrition 13, 614-619.

Smith RC \& Hartemink RH (1988) Improvement of nutritional measures during preoperative parenteral nutrition in patients selected by the prognostic nutritional index: A randomized controlled trial. Journal of Parental and Enteral Nutrition 12, 587-591.

The Veterans Affairs Total Parenteral Nutrition Cooperative Study Group (1991) Perioperative total parenteral nutrition in surgical patients. New England Journal of Medicine 325, 525-532.

Thompson BR, Julian TB \& Stremple JW (1981) Perioperative total parenteral nutrition in patients with gastrointestinal cancer. Journal of Surgical Research 30, 497-500.

Von Meyenfeldt MF, Meijerink WJHJ, Rouflart MMJ, Builmaassen MTHJ \& Soeters PB (1992) Perioperative nutritional support: a randomized clinical trial. Clinical Nutrition 11, 180-186.

Wicks C, Somasundaram S, Bjamason I, Menzies IS, Routley D, Potter D, Tan KC \& Williams R (1994) Comparison of enteral feeding and total parenteral nutrition after liver transplantation. Lancet 334, 837-840.

Windsor ACJ, Kanwar S, Li AGK, Barnes E, Guthrie JA, Spark JI, Welsh F, Guillou PJ \& Reynolds JV (1998) Compared with parenteral nutrition, enteral feeding attentuates the acute phase response and improves disease severity in acute pancreatitis. Gut 42, 431-435.

Windsor JA \& Hill GL (1988) Risk factors of postoperative pneumonia: the importance of protein depletion. Annals of Surgery 208, 209-214.

Woolfson AMJ \& Smith JAR (1989) Elective nutritional support after major surgery: a prospective randomized trial. Clinical Nutrition 8, 15-21.

Yamada N, Koyama H, Hioki K, Yamada T \& Yamamoto M (1983) Effect of postoperative total parenteral nutrition (TPN) as an adjunct to gastrectomy for advanced gastric carcinoma. British Journal of Surgery 70, 267-274.

Young B, Ott L, Twyman, Norton J, Rapp R, Tibbs P, Haack D, Brivins B \& Dempsey R (1987) The effect of nutritional support on outcome from severe head injury. Journal of Neurosurgery 67, 668-676. 